\title{
INVESTIGAÇÃO DE NORMAS DA FUNDAÇÃO CASA - SP À LUZ DAS CONTRIBUIÇÕES DO PSICANALISTA D. WINNICOTT SOBRE PRIVAÇÃO E DELINQUÊNCIA
}

\author{
Fabiana Zanardo Ferreira, Fabio Camargo Bandeira Villela \\ Universidade Estadual Paulista-UNESP, Curso de Pedagogia, Presidente Prudente, SP. Email: \\ fabianazanardo@gmail.com. \\ ICSB - PROPE/UNESP
}

\section{RESUMO}

A agressividade de jovens é um problema real e complexo, que devemos levar em conta. Para profissionais que trabalham com criança e, especialmente, com crianças que se encontram em situação de atendimento socioeducativo, cabe procurar entender os processos pelos quais passaram esses jovens, para chegar a cometer infrações que os levaram a ser internados em instituições de menores infratores. Nossa intenção com esse trabalho foi a de compreender esse processo a partir das contribuições de Winnicott e com uma análise e estudo dos documentos que regem a fundação casa pensar nos efeitos que o tratamento recebido nessas instituições tem sobre os jovens. O trabalho tem natureza bibliográfica e foi construído a partir de textos de Winnicott e de documentos norteadores do atendimento de menores internados na Fundação Casa - SP.

Palavras-chave: socioeducativo, deprivação, delinquência, Winnicott, Psicanálise

\section{INVESTIGATION OF THE RULES OF THE FUNDAÇÃO CASA - SP CONSIDERING THE CONTRIBUTIONS OF PSICANALIST D. WINNICOTT ON PRIVACY AND DELINQUENCY}

\begin{abstract}
The aggressiveness of young people is a real and complex problem that we must take into account. For professionals who work with children and especially with children who are in a situation of socio-educational care, it is necessary to understand the processes through which these young people passed, in order to comprehend their behavior and committed infractions that led them to be institutionalized in juvenile offenders' institutions. The aim of this work is understanding this process from Winnicott's contributions taking on account major documents governing the Fundação Casa - SP to think about the effects of the treatment received in these institutions on young people. The research is bibliographical and was constructed from Winnicott 's contributions confronting them with the documents guiding the care of young people hospitalized at the Fundação Casa - SP.

Keywords: socioeducative, deprivation, delinquency, Winnicott, Psychoanalysis
\end{abstract}




\section{INTRODUÇÃO}

A presente pesquisa foi realizada com o apoio da teoria formulada pelo psicanalista inglês Donald Woods Winnicott e tem o propósito de investigar o documento do regimento interno da Fundação Casa - SP, a partir das contribuições do autor. Após realizar a leitura do livro de Winnicott, intitulado Privação e Delinquência, que aborda a condição e o tratamento de jovens com deprivação (entre os quais costumam estar os jovens infratores), bem como a leitura do Estatuto da Criança e do Adolescente (Eca) e do Regimento Interno da Fundação Casa - SP, buscamos estabelecer relações entre os textos normativos dessa instituição e os escritos teóricos de Winnicott.

Winnicott estudou o desenvolvimento de crianças normais, bem como a deprivação no período da infância, que, para ele, acontece na situação de uma criança ter um bom ambiente, uma boa experiência familiar e, por um ou outro motivo, perder o contato com esse ambiente terno e de cuidados, ou seja, ter sido privada de sua boa experiência e confiança no ambiente familiar. Essa condição, que ele chama de deprivação, seria a principal causa dos comportamentos antissociais e da delinquência.

\section{METODOLOGIA}

O presente artigo foi desenvolvido a partir de pesquisa de iniciação de natureza bibliográfica, que consistiu na análise de documentos relacionados ao atendimento socioeducativo de jovens da Fundação Casa - SP diante de contribuições de Winnicott sobre o tema de privação e comportamento antissocial. O texto original, aprovado como relatório de Iniciação Cientifica, conta, ainda, com dois tópicos intitulados A deprivação e Agressividade, fugas e punições.

\section{DESENVOLVIMENTO}

Sabemos que a delinquência juvenil é um grave problema, que atinge um número amplo de crianças, jovens e adolescentes. Uma das formas que a sociedade usa atualmente para lidar com esses jovens é a de retirá-los do convívio social. No entanto, delinquência e exclusão do convívio social são problemas graves e complexos e que precisam ser refletidos e equacionados pela sociedade.

A educação tem encontrado dificuldades no desenvolvimento emocional do aluno considerado normal e parece ser muito mais desafiador lidar com crianças e jovens que apresentem um claro quadro de deprivação.

Para nós, é difícil imaginarmos um sistema educacional sem falhas; mais difícil ainda se torna imaginar um sistema que trabalha com jovens privados de sua liberdade por má conduta em sociedade, por determinação da Justiça, em uma situação de restrição de liberdade para menores, com seu afastamento do convívio social - portanto, à semelhança de uma prisão - e entendido por eles exatamente como isso.

Não existe um perfil ímpar quando tratamos dos jovens que são pegos cometendo os atos infracionais. A grande escassez de recursos em que vivem alguns jovens pode ser um dos motivos que estimulam os atos infracionais, mas existem questões que estão além disso; em alguns momentos, esses jovens estão buscando na sociedade algo que lhes falta emocionalmente, como veremos no decorrer deste trabalho.

No seio familiar, é preciso encontrar afeto, ternura e firmeza por parte das pessoas que proveem seus cuidados. Apenas com a constância desses cuidados é que será possível para a criança ter um bom desenvolvimento e, assim, tornar-se um jovem independente e sem maiores complicações em sua vida adulta. É a constância desses cuidados que contribui para evitar que elas cometam atos antissociais graves e reiterados, e que, para esse autor, estão basicamente relacionados com a privação de cuidados essenciais. Segundo o autor (WINNICOTT, 2005, p. 64), "o desenvolvimento emocional dos primeiros anos é complexo e não pode ser omitido, e toda 
criança necessita absolutamente de um certo grau de ambiente favorável se quiser transpor os primeiros e essenciais estágios desse desenvolvimento".

Winnicott afirma, também, que uma criança que sofre privação passa a buscar sua melhora através de atos antissociais. Esse procedimento é uma forma de esperança, uma espécie de pedido de ajuda da criança para o ambiente em que está inserida e, até mesmo, para a sociedade. Esses atos deveriam, então, ser aproveitados e trabalhados para que os jovens tivessem, de fato, a oportunidade de conseguir um alívio em relação ao desapossamento que tiveram e pudessem obter avanços em seu desenvolvimento. No caso do jovem que vê nesses atos antissociais uma forma de obter ganhos secundários para si, esses ganhos farão com que se afastem da busca por sua melhora e tornem mais difícil a superação do sentimento de perda.

$\mathrm{O}$ ato de retirar uma criança de sua casa é, para Winnicott, algo que tem grande chance de fracassar, já que, segundo o autor, a criança necessita de um bom ambiente, com pessoas que se mostrem preocupadas com ela para se desenvolver e, quando acontece alguma falha ambiental, esse mesmo ambiente deveria ser capaz de voltar a ser confiável. Isso justifica o motivo pelo qual ele considerava que a retirada das crianças de suas casas não deveria ser senão excepcional. O lar costuma ser o melhor lugar para uma criança e, mesmo que não seja perfeito, nele é possível encontrar o que a criança necessita para que seu desenvolvimento ocorra.

O ECA - Estatuto da Criança e do Adolescente - é o documento que prevê os direitos e deveres das crianças e dos adolescentes no Brasil. Esse documento é recente em termos históricos, está em vigor desde1990: ele dispõe normativamente proteção a todas as crianças e adolescentes, sendo crianças meninos e meninas de até doze anos incompletos e adolescentes dos doze aos dezoito anos. Em casos excepcionais, as normas do ECA podem ser aplicadas para pessoas até 21 anos. Para que isso ocorra, é levado em consideração a idade do jovem no momento em que comete $\mathrm{o}$ ato infracional. Se um jovem comete um ato infracional antes de completar os 18 anos, por exemplo, ele será avaliado de acordo com o ECA.

Art. 2 o - Considera-se criança, para os efeitos desta Lei, a pessoa até doze anos de idade incompletos, e adolescente aquela entre doze e dezoito anos de idade.

Parágrafo único. Nos casos expressos em lei, aplica-se excepcionalmente este Estatuto às pessoas entre dezoito e vinte e um anos de idade (BRASIL, 1990).

É importante que os regimentos das fundações que tratam de crianças estejam de acordo com o ECA, pois ele prevê direitos essenciais para a criança e para o jovem que eram negligenciados, ainda que hoje seja possível encontrar casos em que os direitos básicos da criança e do adolescente estejam sendo descumpridos, mesmo com a existência dessa lei. A garantia dos direitos da criança e do adolescente está contemplada nas duas classes de documentos acima citadas. No ECA encontramos:

Art. 3ㅇ - A criança e o adolescente gozam de todos os direitos fundamentais inerentes à pessoa humana, sem prejuízo da proteção integral de que trata esta Lei, assegurando-se Ihes, por lei ou por outros meios, todas as oportunidades e facilidades, a fim de Ihes facultar o desenvolvimento físico, mental, moral, espiritual e social, em condições de liberdade e de dignidade (BRASIL, 1990).

Em termos semelhantes, dispõe o Regimento Interno da Fundação Casa - SP. Segundo o artigo 2ㅇ, "o atendimento deverá garantir a proteção integral dos direitos dos adolescentes, por meio de um conjunto articulado de ações governamentais e não governamentais, da União, Estado e dos Municípios". (SÃO PAULO, 2012)

É no ECA, também, que estão previstas quais medidas devem ser tomadas em relação àqueles jovens que cometerem atos infracionais: crimes ou contravenções penais. Entre essas medidas, estão desde a advertência, o reparo pelo dano causado, o trabalho comunitário em sociedade até a internação, que pode ser total ou de semiliberdade. $O$ estatuto prevê, ainda, que a medida aplicada deve ser aquela que a criança tem condições de cumprir, conforme o inciso 1 
do artigo 112: " 1 ${ }^{\circ}$. A medida aplicada ao adolescente levará em conta a sua capacidade de cumprila, as circunstâncias e a gravidade da infração." (BRASIL, 1990)

No ECA também está previsto que cada instituição destinada aos cuidados de crianças e jovens deve ter seus regulamentos internos, levando em conta todos os direitos assegurados às crianças e aos adolescentes por lei, com a previsão de punição e cassação.

Art. 90. As entidades de atendimento são responsáveis pela manutenção das próprias unidades, assim como pelo planejamento e execução de programas de proteção e socioeducativos destinados a crianças e adolescentes, em regime de: I - orientação e apoio sócio-familiar; II - apoio sócio-educativo em meio aberto; III - colocação familiar; IV abrigo; V - liberdade assistida; VI - semiliberdade; VII - internação (BRASIL, 1990).

Tal como é previsto, cada Fundação Casa tem seu regulamento interno. Para esse estudo, utilizamos o documento da Fundação Casa - SP, publicado em 2012. Esse documento traz quais são as normas de funcionamento, como deve ser realizado o atendimento do jovem, desde sua entrada na instituição; como devem proceder os funcionários e quais são os direitos e deveres dos jovens enquanto membros da instituição, além de quais medidas devem ser tomadas quando algum dos deveres for descumprido.

Foram diversas as mudanças até que se chegasse ao modelo de Instituição que existe atualmente. Até o ano de 2005, o atendimento aos jovens no Estado de São Paulo era centralizado na capital. No ano de 2006, houve um programa de descentralização, que passou a atender esses jovens no interior. Para que isso se tornasse de fato possível, foi necessária a construção de novas unidades da instituição.

Assim, a Fundação Casa - SP atualmente deixa as crianças mais próximas das famílias, o que é um direito garantido por Lei. Conforme o parágrafo primeiro do artigo 92 do ECA: "Art. 92. As entidades que desenvolvam programas de abrigo deverão adotar os seguintes princípios: I preservação dos vínculos familiares". Tal medida é algo essencial para que a criança ou o jovem possa se desenvolver bem. Veremos que a principal maneira de ajudar as crianças que estejam passando por dificuldades emocionais é, na grande maioria das vezes, mantê-las próximas de um ambiente que lhes proporcione firmeza e afeto, no caso, a família. Como nas hipóteses em que a internação é determinada não é possível mantê-las no seio da família, é bom que seja possível deixá-las mais próximas da família, e não como acontecia anteriormente, levando-as sempre para a capital do Estado.

Atualmente, entre as medidas socioeducativas previstas no ECA, são de responsabilidade da Fundação Casa - SP a internação e a semiliberdade; a liberdade assistida é atualmente atribuição do município. Como previsto no ECA, quem define qual a medida socioeducativa que o jovem classificado como infrator irá receber é o juiz para o qual ele é encaminhado.

O Regimento Interno da Fundação Casa - SP está escrito de acordo com o documento do ECA. No que diz respeito ao documento, os direitos dos jovens estão garantidos e sua condição de ser humano em desenvolvimento é levada em conta. Apesar disso, sabemos que a Fundação Casa - SP conta com uma rotina intensa para os jovens, que têm horário para dormir, acordar e realizar diversas atividades durante o dia. Além da rotina, esses jovens vivem sob a condição das punições, que são divididas em graus de menor até maior severidade e que são aplicadas como medidas para aqueles que descumprem as normas disciplinares da Instituição. As punições para as faltas estão previstas no capítulo VI do regulamento disciplinar do documento do Regimento Interno da Fundação Casa - SP.

Artigo 53 - Não haverá falta nem sanção disciplinar sem expressa e anterior previsão legal ou regulamentar.

$\S 1$ ㅇ - As sanções disciplinares têm caráter educativo e respeitarão os direitos fundamentais e a individualização da conduta do adolescente.

$\S 2$ - $\mathrm{O}$ adolescente não poderá ser responsabilizado, mais de uma vez, pelo mesmo fato. 
$\S$ 3o - São vedadas sanções que impliquem em tratamento cruel, desumano ou degradante (SÃO PAULO, 2012).

Segundo Winnicott (2005), a angústia gerada nas crianças que foram retiradas de seu lar e que estão nesses ambientes pode aumentar as chances de que tenham mau comportamento e as punições podem acabar não surtindo o efeito sobre elas, não interrompendo tais atitudes de rebeldia. Com isso, não estamos afirmando que um jovem que ultrapassa os limites das regras esteja imune a quaisquer punições. As punições devem ser pensadas a partir da situação em que o jovem se encontra, do quanto ele ainda pode suportar emocionalmente e não apenas ser aplicada pelo ato cometido.

É necessário aos jovens entenderem que para conviver em sociedade existem regras. Apresentar atitudes que não estejam de acordo com o que é estabelecido normativamente, como o jovem pegar para si objeto que não lhe pertence, pode resultar em uma penalidade. Punir também deve ser feito como um ato de afeto, e por alguém que realmente se preocupe com o jovem, portanto, em dose certa e sem desistir do jovem. Assim, será possível que essa punição favoreça seu desenvolvimento emocional.

Apoiando-nos, mais uma vez, no que Winnicott afirma em seu livro Privação $e$ delinquência, temos a ideia de que o ato antissocial pode variar: vai desde a gula e a enurese, até mesmo a atos ou sintomas mais graves como perversões sádicas e psicopatias. A produção de tais atos, em grande parte, depende do quão bom era o ambiente que o jovem teve e perdeu e de como ele reagiu a esse desapossamento. Dessa forma, alguns jovens com comportamentos antissociais são pegos pela lei e submetidos às instituições socioeducativas, enquanto outros não. Winnicott (2005) destaca a conduta do furto, como uma das principais causas que faz com que os jovens cheguem até os tribunais.

Para Winnicott (2005), muitos desses jovens estariam buscando aquilo que tiveram e perderam, mas que imaginam ser seu por direito e que the deve ser restituído de alguma forma, seja através de furtos no próprio seio familiar, seja no âmbito mais amplo da própria sociedade.

A tendência antissocial pode ser observada no próprio filho saudável que, aos dois anos de idade, subtrai uma moeda da bolsa da mãe. A tendência antissocial resulta sempre de uma privação e representa a reivindicação da criança para retornar ao estado de coisas existentes quando tudo estava bem. (WINNICOTT, 2005, p. 277)

Não podemos deixar de considerar que existem outros fatores que influenciam os jovens a cometer atos infracionais. Sabemos que muitos dos nossos jovens são expostos a situações de vida precária, com desigualdades difíceis de aceitar e, muitas vezes, sem os cuidados básicos para a sobrevivência. O que fica visível é que o histórico da perda e busca de cuidados e de amor dos pais ou pessoas muito próximas afetivamente marca esses jovens e os impulsiona para essas situações. Levando em conta a formulação de Winnicott sobre o bom ambiente como fundamental ao bom desenvolvimento emocional da criança, esse ambiente deveria estar sendo garantido pelo Estado e pelo próprio entorno familiar.

\section{DISCUSSÃO}

É importante pensar em soluções para amenizar os problemas das crianças que passam por condutas antissociais, mas temos visto que soluções repressivas por si só não são capazes de ajudar na sua solução. Aqui trabalhamos com a ideia de que esses são pedidos de socorro, quase que um refúgio para crianças e jovens que, em algum momento, se viram privadas de cuidados básicos e, em muitos casos, existe a imensa desigualdade social como um forte fator agravante.

Os cuidados e o respeito ao seu desenvolvimento também são direitos da criança e do adolescente e estão garantidos e previstos no ECA, conforme o artigo 15: "Art. 15. A criança e o adolescente têm direito à liberdade, ao respeito e à dignidade como pessoas humanas em 
processo de desenvolvimento e como sujeitos de direitos civis, humanos e sociais garantidos na Constituição e nas leis". (BRASIL, 1990)

Ao fazer uma análise desse documento junto ao documento do regimento interno da Fundação Casa - SP, foi possível perceber que os textos descritos levam em conta direito básicos da criança que são importantes para seu crescimento sadio, bem como a proximidade familiar como citamos acima e o direito a um atendimento individual, quando o jovem ingressa na instituição que torna possível respeitar suas características individuais.

Visto que os direitos assegurados levam em conta o desenvolvimento das crianças, é importante ainda frisar que cada ser tem características individuais e, assim, devem considerar a individualidade de cada uma.

\section{CONCLUSÃO}

As instituições para os menores que cometem atos infracionais podem ser boas para eles se forem administradas da forma correta e trabalhem com eles de forma firme, sem sentimentalismo, mas com afetividade sincera. Os documentos que regem essas instituições devem ser criados, modificados e efetivados, sempre por pessoas que estejam cientes desse delicado processo de amadurecimento das crianças e jovens.

Os documentos analisados para essa pesquisa levam em conta as características da criança como ser em desenvolvimento e podem garantir que, mesmo aquelas crianças que passam por dificuldades emocionais e necessitam de auxílio, tenham um bom desenvolvimento. Podemos considerar que esses documentos devem ser lidos de forma a evitar lacunas para que algum desses direitos seja negligenciado e, ainda, que a interpretação sobre o texto de tais direitos seja sempre a de considerar as crianças como seres individuais e que precisam ser tratadas com firmeza e afeto no ambiente em que vivem.

\section{REFERÊNCIAS}

BRASIL. Estatuto da Criança e do Adolescente, Câmera dos Deputados, Lei no 8.069, de 13 de julho de 1990. DOU de 16/07/1990 - ECA. Brasília, DF.

SÃO PAULO. Fundação Casa. Portaria 224/2012, de 07 de maio de 2012 (Regimento Interno dos centros de internação e semiliberdade da Fundação Casa - SP, 2012.

WINNICOTT, D. W. Privação e delinquência. 4. Ed. Martins Fontes. 2005. 